\title{
Cruising with(out) a conscience? Sustainable discourse in the blogosphere
}

\begin{abstract}
Cruise tourism is on its way to becoming the new mass tourism and hospitality product. However, existing research on the sustainability of the cruise industry reveals negative impacts often outweigh the positive. Criticism includes for example, unequal distribution of economic benefits, environmental pollution, and unfair working conditions, this latter being an issue which is also relevant to the wider hospitality industry. While previous research mainly focuses on the economic and environmental impacts of ocean cruising and how these can be managed by the industry and destinations alike, it is not known whether cruise tourists acknowledge any responsibility to maximize the positive impacts and mitigate the negative impacts of their cruise holiday. Based on a blogpost-analysis conducted in a travel blog community of more than 200,000 members, the study sought to understand whether cruise tourists reflect on the sustainability of their holiday. Findings reveal cruise tourists reflect upon the sustainability of their cruise, but do so unconsciously and largely superficially. However, this paper argues an examination of these limited reflections reveals insight that can be used to develop more effective ways to encourage passengers to be critically aware of industry practices, foster a social conscience and possibly advocate for a more sustainable cruise industry.
\end{abstract}

\section{Introduction}

This study explores and critically evaluates whether cruise tourists discuss sustainability (environmental, social, and economic dimensions) on their personal travel blogs. The perceived unsustainability of the cruise industry has received increased attention in the popular press (Watson 2015), corporate marketing communications (see e.g. Jones et al. 2017), and academia (see e.g. Johnson 2002; Lester and Weeden 2004; Klein 2009; 2011; Weeden et al. 2011; Maher 2012; Bonilla-Priego et al. 2014; Weeden 2015). What remains unknown is whether passengers consider the wider impacts of their cruise travel, such as their carbon footprint, whether their expenditure in port benefits local communities, and whether ship staff receive a fair wage.

Besides traditional forms of marketing and word of mouth, tourists increasingly make holiday decisions based on information retrieved from the Internet. In their 25-year review of sustainable tourism research, Bramwell et al. (2017) call for more attention on how people interact within grand socio-technical structures, especially focusing on interconnections within online social networks. These include tourismrelated forums, reviewer rating sites (e.g. TripAdvisor), social networking sites (e.g. Travellerspoint), generic social media platforms (e.g. Facebook), as well as blogs (Mkono 2012; 2016a). Considered a rich 
source of data (Zehrer et al. 2011; Chen et al. 2014; Bosangit et al. 2015; Kurtz et al. 2017), blogs are online public journals or diaries, single-authored and/or written collaboratively, that tell stories and provide information, largely beyond mainstream media (Gauntlett and Horsley 2004; Olive 2012). Blogs are powerful conduits for social scientists to investigate 'personalized narratives, performative spaces, and selfreflective commentaries for both the blog writers themselves and the readers with whom they establish relationships' (Kurtz et al. 2017: 3). Such narrative reflections can offer unprompted insight into what individuals consider essential to communicate (Snee 2013a) as they construct a virtual identity (Bosangit et al. 2015). Whilst written specifically for an audience, to elicit feedback, and/or develop social networks (Kurtz et al. 2017), the inherent anonymity of most blog forums encourages bloggers to be less selfconscious about their posts. Arguably this also reduces social desirability bias (see Auger and Devinney 2007). Additionally, the personalised, confessional nature of blogs (Hookway and Snee 2017) offer researchers a window into tourists' search for meaning from travel experiences through self-reflection (Carù and Cova 2006). As such, they are useful to scholars seeking to understand passengers' reflections on their cruise experiences. Significantly, whilst tourists regularly document their leisure activities on social media, travel blogs remain less used as sources of research data (Bosangit et al. 2015).

The structure of the article is as follows. A literature review discusses sustainability in tourism and hospitality generally before focussing on how the topic has been addressed in cruise scholarship. It continues with an exploration of how sustainability has been discussed on social media platforms and travel blogs, concluding with research gaps and the aims of the study. Research methods are presented, followed by the results, reporting first on the social and economic dimensions of sustainability and second, on its environmental aspects. A critical discussion follows with recommendations for practical application to the sector and for future scholarly research.

\section{Sustainability in tourism}

Sustainability in tourism and hospitality continues to be a key challenge for society (see Bramwell et al. 2017; Cavagnaro et al. 2018). Whilst its origin can be traced back to the Brundtland Report of 1987, the three dimensions of sustainability (economic, social and environmental) remain pertinent as evidenced by the UN designation of 2017 as the Year of Sustainable Tourism for Development, and a focus on its promotion of the 17 Sustainable Developments Goals (SDGs). The environmental (ecological) element encompasses natural resource usage, and the preservation and conservation of biodiversity within planetary limits (Lee et al. 2013; Higham and Miller 2018). The social (ethical) dimension refers to tourism's impact on relations between tourists and destination residents (Zhang et al. 2016), as well as, albeit it less so, concerns about the provision of safe, fair and just employment opportunities in tourism and hospitality 
contexts (see Baum 2018). The economic dimension of sustainable tourism seeks to facilitate financial benefit for local communities from tourist expenditure, at the same time as incorporating and accommodating residents' views on tourism development (Garrigós-Simón et al. 2015).

While tourism research has addressed social and economic sustainability, much of the literature focuses on encouraging individual pro-environmental practices (Iaquinto 2015). In particular, many studies centre on the contribution of tourist activity to climate change, discussing the 'gap' between tourists' attitudes towards climate change and their travel behaviour (see e.g. McKercher et al. 2010; Miller et al. 2010; Hanna et al. 2017). Research reveals consumers are increasingly aware of the impacts of their travel behaviour (Higham and Cohen 2011; McDonald et al. 2015; Hanna et al. 2017) but are persistently reluctant to adopt pro-environmental practices on vacation, citing strategies of denial such as a sense of powerlessness to effect change, financial and time restrictions, or a perception they must forego luxury to have a sustainable experience (Juvan and Dolnicar 2014). In line with this, hospitality scholarship reveals hotels often adopt an eco-efficiency perspective towards sustainability because they perceive guests are driven by hedonic motives and only engage in environmental measures if they receive a personal gain (Cavagnaro et al. 2018). In their own study however, Cavagnaro et al. (2018) found Dutch hotel guests had a more comprehensive understanding of sustainability, asserting hotels needed to think also about their economic and social responsibilities by using cruelty-free food and ensuring employees' working conditions were fair. Some also had an expectation that a hotel should undertake philanthropic activities in local communities.

Despite these valuable insights, critical understanding of tourist attitudes towards the impacts of their travel across all three pillars of sustainability is scarce, with no evidence of this in regard to cruise passengers. However, the growing economic significance of cruise for the wider tourism and hospitality industry means that an exploration of passenger awareness of the sustainability of cruising is essential.

\section{Ocean cruising and sustainability}

The cruise industry has proliferated over the past decade (Seatrade Cruise 2017), as evidenced by an increase in passengers, new destinations and niche products, and the number and size of new ship builds (Dowling and Weeden 2017). Over 24 million people chose a cruise for their holiday in 2016, and with 75 new ship builds on order, passenger numbers are estimated to rise to 35 million by 2026 (Seatrade Cruise 2017). Such intensive development has led to concerns over the sustainability (social, economic and environment) of cruising (see Sheppard 2010; Hall et al. 2017). For instance, with regard to the environmental dimension, an increase in the number of ships able to carry 5,000-6,000 passengers and 2,500 crew require ports across the globe to consider how such vessels can be accommodated (London et 
al. 2017). These mega-ships also create onshore challenges for resident communities, contributing to overcrowding (or overtourism) in popular European cruise destinations, such as Barcelona, Dubrovnik and Venice. Such 'people pollution' (Baekkelund, 1999, in Klein, 2011: 112) negatively impacts a destination's infrastructure, contributing to shortages of fresh water and excessive demand on waste management systems. Further adverse impacts include deterioration of coastal waters and increased pollution from cruise ship emissions in port (Hall et al. 2017), contributing to port community resentment potentially negative experiences for cruise passengers.

Looking first at the economic element of sustainability for cruise tourism, consensus on the financial benefit accruing to ports from visiting cruise ships is notably absent. On the one hand, industry association CLIA (2017) claim 129.4 million onshore visits by passengers and crew in 2016 generated $\$ 57.9$ billion, with passengers spending between $\$ 94$ - $\$ 140$ per head depending on whether they were in a transit or home port. On the other hand, critical sources argue cruise passengers spend the least of all tourists in a destination, largely due to the limited time they spend ashore, around 5-8 hours (Brida and Zapata 2010; Larsen et al. 2013). The dominant economic model for cruise lines is predicated on passengers spending money onboard rather than ashore, and in combination with the ship being the destination (see Wood 2000), many cruisers return to the ship for lunch as opposed to spending money in local restaurants, bars and hotels. Klein (2011: 111) concurs, stating 'while cruise tourism brings many more visitors, its economic impact is relatively small and contracted in a few hands.' For the Caribbean, the world's most popular cruise region, this is especially damaging. Discretionary spend per cruise ship passenger in the area is not only in overall decline but estimates indicate passengers spend $82 \%$ of their money on-board ship and only $18 \%$ ashore (MacLellan 2016). Similarly, MacNeill and Wozniak (2018) found little evidence of predicted gains in employment or income from cruise visits in their study of Trujillo, Honduras.

Of major interest to a socially sustainable cruise industry are concerns over the pay and working conditions of hotel staff on-board (see Terry, 2011). Lower skilled staff (dining and bar staff, cabin stewards) in hotel services work long 'flexible' hours for very low wages with few benefits, on extensive and non-secured contracts (Chin 2008). Almost 70\% come from relatively poor, low wage countries in South and South East Asia, Central America, the Caribbean and Eastern Europe (Terry 2017). While various media have brought these to the attention of the wider public (see Frantz, 1999; Channel 4, 2012), the sensitivity of the cruise industry towards any critical comment on its labour practices means few independent researchers are granted permission to access employees for research. These labour practices exist due to the maritime industry adoption of open and second registries, also known as flags of convenience (FOC). Under this scheme cruise lines register ships in countries such as the Bahamas, Bermuda, Panama, or Malta, to benefit 
from agreements with minimal taxation rates, weak legislation on environmental and labour practices, and a freedom to recruit internationally (Wood 2000; Terry 2011, 2017; Nilan et al. 2014). For cruise employees, FOCs mean formal employment periods range between three and twelve months, usually followed by a four to eight-week unpaid period, often referred to as 'vacation' even though companies are not required to rehire once a contract has ended (Chin 2008; Terry 2011). Similarly, staff are recruited 'on ethnicity, race and gender' (Terry 2011: 632). This is of significance not only because these jobs are usually more highly paid than those without customer interaction, but also because they contradict the principles of social sustainability identified above. Furthermore, cruise lines, sometimes more than other forms of hospitality employment, expect staff to work long hours over many months without a rest day, whilst simultaneously presenting themselves as positive, cheerful personalities who must exhibit these qualities even when off duty (Tracy 2000). Such characteristics are reminiscent of Hochschild's (1983) concept of emotional labour, where workers must manipulate their emotions and physical appearance to present a positive experience for passengers. Emotional labour is particularly pertinent for those working on a cruise ship, as well as some sectors of the wider hospitality industry, because staff are forced to rely on passenger gratuities to supplement extremely low wages. This, in combination with the physical limitations of the ship, can make working on-board a demanding and emotionally draining work experience, which can lead to resentment of passengers by cruise ship staff (Nilan et al. 2014). Tracy (2000: 92), in reference to Goffman (1961), describes cruise ships as 'total institutions' where emotions and feelings are regulated in a more totalising manner than in land-based work settings. Such commodification of cruise staff emotion thus calls into question the social sustainability of the industry.

Of significant additional debate regarding sustainable cruise tourism are the environmental impacts of cruise ship tourism, distinguished between on-board ecological considerations, shore-based systems and impact on the marine environment. On-board factors include recycling of plastics, solid waste and water treatments and emissions from burning fuel. Shore-based and marine impacts include those caused by port and tourism infrastructure development, or cruising in environmentally sensitive areas (Dowling and Weeden 2017; Hall et al. 2017; van Bets et al. 2017).

As already noted in regard to the wider tourism and hospitality literature, the majority of studies examine a single aspect of sustainability. Similarly, there is little evidence of cruise scholarship that takes a comprehensive approach to the complex interconnections of sustainable practices. A notable exception is MacNeill and Wozniak's (2018) measurement of economic, social and environmental impact of cruise tourism on the port of Trujillo, Honduras using pre- and post-tourism baseline data. While this offers valuable information, there is no research into passenger perceptions and/or narratives about the 
sustainability of their cruise. In contrast, beyond cruise literature, there is evidence of research (although limited) which indicates tourists are increasingly aware of the impact of their travel behaviour and turn to social media to negotiate these with likeminded travellers (Rokka and Moisander 2009; Budeanu 2013). The following section examines these issues in more detail.

\section{Social media and sustainability discourse in tourism}

The Internet is a well-used tool for tourists, not only to search for information about their next holiday but also to engage with others to discuss their travel experiences (Leung et al. 2013). Major changes in consumer behaviour have been precipitated by the development of Web 2.0, most notably through websites, social media and mobile technology (Sotiriadis 2017). Social media, specifically blogs, enable tourists to share information and describe their experiences publicly, thus fostering an increase in the number of people creating 'personal virtual identities' (Munar and Jacobsen 2014: 46). A significant aspect of blogging however, is the opportunity for tourists to connect and interact with others (Oz 2015), with many studies aimed at understanding how this type of electronic word of mouth (eWOM) influences tourist decisionmaking (Leung et al. 2013). Mkono and Tribe (2017) observe tourists use designated online tourism platforms to go beyond reviewing and turn social media into a personal yet public space to socially construct meaning. Of interest to this study is their categorisation of contributors to TripAdvisor as troll, socialite, information seeker, activist or social critic - the latter two being tourists who reflect on and voice concern about their holiday experiences. While activists call for change or the boycott of a particular tourist activity, social critics express opinion and voice concern about the status quo of the tourism system but avoid making direct appeals for change (Mkono and Tribe 2017).

However, literature which examines tourists' use of social media to discuss the sustainability of their travel behaviour, and how to become more socially and environmentally friendly, is limited (see Bramwell et al. 2017). Notable exceptions include Rokka and Moisander's (2009) study of an online community of 'global travellers' whose discussions of sustainable tourism concerned the social and environmental consequences of travel. They conclude that research into online travel communities can facilitate greater environmental understanding and thus prompt new forms of active ecological citizenship (Rokka and Moisander 2009). Similarly, social media can facilitate change through shared reflexivity which may challenge tourists' personal frames of references regarding moral responsibilities on holiday (Mkono 2016b). Jansson (2018) also noted the importance of researching tourists' reflexivity, but linked this to 'spreadable' social media (such as Facebook, TripAdvisor, and travel blog posts, where information is easily shared among different online communities), in order to reveal how individual's think about sustainability. Yet, 'the idea that social media can be a tool for social criticism has not been sufficiently acknowledged in tourism research' (Mkono 
and Tribe 2017: 295). Bosangit et al. (2015) concur, arguing travel blogs are under-utilised to explore how tourists reflect on their holiday experiences.

In conclusion, Bramwell et al. (2017) identify the importance of framing sustainable tourism, noting research has largely focused on individual behaviour instead of interaction within large socio-technical structures and their resultant complex interconnections. Further, they suggest it is imperative to explore whether tourists contribute to wider societal changes using these online spaces. Bosangit et al. (2015) question how (cruise) tourists reflect upon holidays in blogs to create a more personally meaningful and thus transformational experience. Indeed, blogs reveal narrations of lived experiences, beliefs and attitudes (Woodside 2010), thus generating patterns which may reveal the degree to which sustainability plays a role in cruise passengers' reflections. As such, blogposts render themselves as potential tools of great value to achieve release from dissonance that may relate to questions of sustainability on a cruise. Therefore, this study aims to explore whether cruise passengers discuss cruise sustainability via blogs, using the three dimensions of economic, social and environmental as a guiding framework. It further examines whether these online spaces provide opportunities for bloggers to become reflexive about the impacts of their cruise and considers whether such reflections might influence their future travel behaviour.

\section{Method: identifying sustainability discourses}

To address the aims of the study, cruise passenger narratives in the form of blogposts were selected from a travel blog portal that features over 200,000 members from across the world. The portal features posts written mainly in English and accessible to travellers throughout the world who are interested in sharing their experiences online. Members of the portal can create a personal travel blog, choosing a nickname or registering with a Facebook account. The default settings of the portal can be personalised, allowing bloggers to upload pictures and personal profiles, number of trips taken and so on. Bloggers are able to engage with each other via a forum, follow others and leave comments on people's blog entries at the end of each post. Individuals can create single posts about a trip, or have several posts relating to one vacation.

In this study, a blog is understood as a non-commercial, personalised site (similar to a Facebook profile), where individuals can post text, audio, video and picture material, all of which are referred to as blogposts here. To find relevant posts, keywords using everyday language to inform tourists about sustainability (see Hanna et al. 2016) were selected from webpages of responsibletravel.com (Mack n.d.) and Tourism Concern (2016). The former revealed terms used to explain the wider concept of responsible travel, whilst the latter elicited words to communicate the ethical dilemmas associated with cruising. These keywords are 
shown in Table 1, and presented according to the different dimensions of sustainability. Blogposts were selected using the search function provided on the blog community's website.

Table 1: Keywords selected to facilitate blog search

\begin{tabular}{|c|c|}
\hline Dimension of sustainability & Selected keywords \\
\hline Environmental/ ecological & $\begin{array}{l}\text { - ecology, environment, green, natural, } \\
\text { landscape, seascape } \\
\text { - local food, food waste } \\
\text { - recycling, pollution, resources, energy, } \\
\text { carbon footprint, waste }\end{array}$ \\
\hline Social / ethical & $\begin{array}{l}\text { - local community } \\
\text { - } \text { respect, guilt, conscience, responsible, } \\
\text { ethical } \\
\text { - authentic, dilemma } \\
\text { - } \text { support, donation, volunteer }\end{array}$ \\
\hline Economic/ financial & $\begin{array}{l}\text { - price, money, import, profits, economy, } \\
\text { cost, cheap } \\
\text { - employees, staff, waiter/waitress, crew }\end{array}$ \\
\hline
\end{tabular}

In addition, and following Snee (2010), in order to be selected, each blogpost had to satisfy the following criteria:
a) written by a cruise tourist, in English
b) posted between January 2010 and July 2017
c) focused on ocean cruising
d) author not directly or indirectly affiliated to the cruise industry
e) be publicly available

This process revealed 2,680 blogposts. Each of these were inspected to ensure keywords aligned with aspects of sustainability as discussed in the literature. Such refinement was essential - for instance, two bloggers used ethical when they were describing ethnicity, while the search word guilt revealed a tourist reflecting on feeling guilty about eating too much at dinner. Similarly, a dilemma post related to a passenger unable to decide which on-board recreational activity was best for them. This systematic process of inspection (see Hookway and Snee 2017) rendered a reduced sample of 21 posts from twenty different bloggers, ranging from 200 to 2,500 words in length. Within these narratives, sections with keywords related to sustainability ranged from 25 to 650 words. 
Many of the blogposts in the sample were written in the plural, talking about our cruise, our experience, our time on the cruise, which made it difficult to identify the nationality, age of the author, or whether the post was single, couple/family or group-authored, even on deeper analysis of information provided by bloggers on their personal profile. In order to address this limitation, it has been assumed that posts were single-authored. The majority of cruises referred to were 'mass market'. Diverse destinations were mentioned: four posts were about cruises in the Caribbean, while three apiece were on cruises in the Mediterranean, South America, Australia and New Zealand. Additional destinations were China, Cambodia, New Caledonia, Papua New Guinea, Philippines, Mexico, Ghana, and Spain. Concentrating the analysis on one or a few specific destinations may have revealed different emphases. However, the aim of this study was to identify whether cruise tourists reflect generically about sustainability rather than identifying how they comment on sustainability in the context of a particular destination. In order to address the ethical dilemma in online research of what is considered to be public and/or private, only blogposts accessible without a password or community account were included in the sample (see Snee 2013b; Hine 2011; Markham and Buchanan 2012). Data collection was completed by the end of January 2018.

Following Hookway and Snee (2017: 388), and in order to reveal if and how aspects of sustainability were discussed, blog posts were subject to thematic analysis, whereby posts were 'read, re-read and organised according to develop[ing] themes.' As mentioned earlier, the posts included for analysis were identified through a keyword search using the website's integrated search engine. Of the 36 search terms, only nine were found in relevant blog posts: ecology, environment, recycling, pollution, donation, volunteer, staff, waiter/waitress, crew. Posts using these keywords were then read online to ensure the context was related to the principles of sustainability as identified beforehand. Although the inclusion of additional posts from bloggers identified by this search may have led to different results, by only including posts with relevant keywords gives the study validity. Furthermore, this may be an indication that the way tourism and hospitality sustainability professionals communicate online may be different to what tourists and hotel guests talk about on social media. Finally, posts were re-read in full to comprehend as much as possible in which context the posts were written. Each post, or sometimes extracts if posts were lengthy, were moved into a word file for coding. Codes were not pre-set but developed and adjusted in an iterative process (see Braun and Clarke 2006), and in line with the research aims. Through this process, themes emerged from the data, with the most dominant being those related to the social and economic aspects of sustainability. The following sections detail the narratives revealed in the blogposts before presenting the analysis in relation to sustainable travel. 


\section{Findings}

Significantly, all blog posts were superficially descriptive, with little evidence of critical reflection. In the following section social and economic aspects of sustainability have been grouped together since there was narrative overlap between the two, with very few solely economic issues noted.

\section{Social and economic dimension}

Search terms staff, waiter/waitress and crew were identified in nine posts. Comments related to staff friendliness, good humour as well as ethnicity. Upon cruising out of Manila harbour one tourist was moved to say, 'The Filipinos are the heart and soul of the [cruise ship] and they represent their country well' (Blogger 7). Another, on a Mediterranean cruise, said, '[...] it is Violet's birthday (although it actually was yesterday), and she was serenaded [by Indonesian wait staff] with the traditional Indonesian birthday song' (Blogger 11). Blogger 2 wrote about his interaction with a Mexican Zumba instructor, and referred to him as a 'superstar.' One tourist posted about Lifou, New Caledonia referring to their enjoying a chance to 'see the natives living in their everyday environment, swimming in the sea, playing football and listening to music in paradise' (Blogger 5). Arguably, these references to ethnicity have connotations of 'Othering' cruise employees, mentioning how 'hardworking' they are or how they entertain people, as highlighted in this excerpt,

'The staff on-board is great. [...] we always laugh with one of the Jamaican waiters who always crows like a rooster as he wheels the coffee cart about the morning buffet. His sense of fun is infectious and he carries it through to the evening [...]' (Blogger 3).

Framing locals and/or service staff as the Other is well conceptualised in the tourism field (see Adler 1989; Scarles 2012; Spracklen, 2013), but has not yet featured within literature on sustainability.

Additionally, in some posts, there was evidence of visited cultures being exoticised. For instance, one passenger reflected,

'Life in this region of West Africa [Togo, Ghana] is not easy, but everywhere you could sense that the people are working hard and love their independence...people proudly display their national flags...and wave and smile at the strangers...Most people live in dishevelled apartments...but they come to the cities looking for work and a better way of life. Traditional African village culture is still out there... some are still living a simple tribal life' (Blogger 10). 
A couple of passengers noted their 'short and sweet' (Blogger 8) time ashore, with one stating 'six hours in a port really just gives you a taste of culture' (Blogger 8), whilst another described the 'few huts and...very simple homes' (Blogger 4) on an Amazon cruise. Yet another recalled time at a school in Belize,

'The teachers, principal and executive director were very friendly and most welcoming. We taught the little ones about Canada...this was the highlight of the cruise, as we really got to see their culture' (Blogger 8).

There were few reflections on the potential impact of the cruise on local cultures, or a consideration of power relations between tourists and locals (Rokka and Moisander 2009). One post briefly commented on the culture of a village in Papua New Guinea being negatively impacted by missionaries but did not mention or seem to consider the impact of their cruise on the village. A different post reflected they were the "rich tourists who have an easy struggle-free life' (Blogger 10), while another queried whether local language and culture might change in Japanese port destinations once cruise ships began to arrive (Blogger 6).

As already noted, several posts concerned passenger encounters with staff, using narratives reminiscent of Hochschild's (1983) emotional labour. Some wrote about staff performance, positively recalling high levels of service, and reflecting on staff financial rewards. Blogger 9 commented that after 15 days of cruising, 'the waiters have been reassigned to different venues and the new crew seemed to be learning the ropes the service was nice but noticeably slower...'. Only one tourist wrote about staff wages,

'[...] there was a question and answer period where lots of people asked about how things are for the crew...we were told that the room stewards and their assistants, as well as the dining room staff and their assistants are paid only in tips, everyone else is salaried...they have full medical [cover] and their only expenses on-board are laundry soap, internet/phone usage, and anything they buy like coffee or whatever (for those who are permitted on the passenger decks)...granted I don't really think this is much of our business but John Heald [brand ambassador] always corrects people who say there's certain crew that just work for tips, so I guess one never really knows who to believe...but in the grand scheme of things, it doesn't really affect my decision on anything...we always leave the autotips ${ }^{1}$ on and always tip anyone else who goes above and beyond' (Blogger 12).

While initially promising to read a reflection on staff wages, the post revealed the author felt little responsibility towards the individuals concerned and did not attempt to unpick the reasons for the situation. 
They also expressed confusion over what to believe, which indicates a slight concern over the potential truth of the issue, although this was quickly dismissed by their claim to abide by the cruise guidelines for tipping. To take this point further, none of the reflections discussed safe, fair or just employment opportunities (Baum 2018; Cavagnaro et al. 2018), long working hours for staff (Chin 2008), or the operation of ships under FOC (Wood 2000; Terry 2011, 2017; Nilan et al. 2014). Of all the aspects of sustainability, emotional labour and the highly demanding conditions of work for hotel staff on-board have been arguably the most discussed in print and broadcast media (see Frantz 1999; Channel 4 2012). It is therefore unfortunate the bloggers in this study appeared to be largely unaware and possibly uninterested in the health and financial wellbeing of the staff they had elsewhere praised for their high levels of attentive service.

Additional dimensions of social sustainability such as relations between tourists and destination residents (Zhang et al. 2016) were only superficially mentioned, and while a few bloggers mentioned shopping opportunities, they were concerned only about the quality of the products available. No other mention was made of how passengers might contribute towards greater economic benefits for destinations (Brida and Zapata 2010; Klein 2011; Larsen et al. 2013; Garrigós-Simón et al. 2015). There was just one exception, where Blogger 10 makes the only reflection to acknowledge the wealth of residents differ significantly from that of cruise ship passengers,

'Very few cruise ships come to these ports and we are the first since last fall. Passengers have been hassled, harassed and one lady had her purse snatched. Yesterday one of the women was told that she was a racist because she did not buy anything. [...] We are considered to be rich tourists who have an easy, struggle-free life. Anyone who is stupid enough to wear expensive jewelry and carry their money in an easy to grab purse is advertising that they have more than they need and really want to make a donation.'

Finally, and possibly related to observations about living conditions in some destinations, search terms volunteer and donation resulted in a few seemingly altruistic posts where passengers claimed onshore excursions inspired them to volunteer in the future. For example, Blogger 8 explained they had brought from home a few 'loot bags' for a local orphanage in Belize and claimed to want to return to volunteer at a later date for 'seven to ten days.' An additional three blogs described the giving of gifts and donations, one to a school in an Amazon village, another in Papua New Guinea and a third to children in Roatán, Honduras. However, they added they had also enjoyed time to 'zipline and play with the monkeys' (Blogger 8). While there is some indication of a transformational experience, these tourists' accounts are highly superficial. It 
is also unknown whether the claimed intention to volunteer would become reality. Although volunteer tourism has been advocated as a meaningful form of sustainable tourism (see McIntosh and Zahra 2007), recent research cautions it can have negative as well as positive impact (Burrai et al. 2017).

\section{Environmental dimension}

The search terms ecology, environment, recycling and pollution were the only words to yield posts related to the environment. Five bloggers mentioned this aspect of sustainability, fewer than those commenting on the social and economic dimensions, and referred only to on-board recycling facilities and pollution in the destination. One blogger, who was visiting a friend working on-board and who gave the blogger a tour of the ship, explained away the ship's emissions by saying they were from the ship's recycling facility,

'[...] she explained to us that the whale tail, which is [X brand's] signature emblem, actually had their own recycling system built into it, which is what the black smoke coming out of the top was' (Blogger $1)$.

Another post explained how waste material such as soda cans were crushed on-board and offloaded on return to the home port, that cardboard was burned at sea and that food waste was 'jetted out to sea.' They further related food packaging could not be recycled and the whole issue of recycling was 'very complicated' (Blogger 12). Significantly, while recycling and waste management systems have been addressed in tourism and the cruise literature (Klein 2009; Iaquinto 2015; Hall et al. 2017), passengers in this blog community revealed little interest in the reality of waste management on-board cruise ships. Neither did they question the veracity of these supposed methods of waste management or reflect on questions related to how waste was recycled or sustainably disposed of. For instance, Blogger 12 proclaimed it 'very complicated,' and none of the bloggers critiqued what they seem to have been told as no posts mentioned seeking further information about waste management processes. Only one blogger discussed pollution, although this concerned how garbage in Cambodia had negatively impacted on their holiday experience,

'The harbour was strewn with garbage and completely downtrodden, we marched our way through and onto the pier in the hopes of finding something better. NOT!...the water was very cloudy and seemed polluted, the beach was strewn with litter' (Blogger 13)

Of the other posts, one alluded positively to the natural environment, highlighting 'vibrant foliage... [and the] ...natural beauty of the glistening turquoise shoreline' (Blogger 14). None of the blogs explicitly 
addressed the environmental impact of cruising or acknowledged bloggers' culpability in generating further ecological degradation, which seems to contradict research that suggests people are increasingly aware of such issues in hospitality and tourism (see Cavagnaro et al. (2018; Higham and Cohen 2011; McDonald et al. 2015; Hanna et al. 2017).

\section{Discussion and Conclusion: Cruising with(out) a conscience}

Initial analysis of these cruise tourists' blogposts reveals only brief and superficial mention of some aspects of economic, environmental and social sustainability. In reality, many of these issues intersect, as was evident in posts that initially described social elements before quickly reflecting on experiences related to issues of economic or ecological sustainability. Arguably, the data indicate some of these cruise tourists referred to sustainability unconsciously, a finding that echoes Iaquinto (2015), who found that backpackers engaged in sustainable practices without realising they were doing so. Thus, while there were few explicit reflections using language used in scholarly research and the media to discuss the three pillars of sustainability, some posts mentioned elements not previously discussed in sustainable cruise literature. For example, where on-board service staff were commented upon, it was not to question conditions of work, a long hours culture, the length and precarity of labour contracts, or staff dependency on gratuities to supplement income, but instead to reveal aspects of 'Othering'. The concept of 'Othering' was also evident in shore experiences, so while posts described local culture and people, they referenced exoticisation, thus commodifying both residents and cruise staff. This aspect supports Spracklen's (2013) commentary on tourists' 'Othering' non-white locals and staff, a process which normalises the hegemonic dominance of whiteness. From the data collected here, it is likely most bloggers were completely unaware of these postcolonial subtly racist narratives and uncritical of the pejorative terms they used to describe staff and residents. With regard to challenging what appears to be a socially unsustainable practice, only one post queried the veracity of what they were told about staff relying on gratuities for income. This form of denial (see Juvan and Dolnicar, 2014), where the blogger expressed being powerless to uncover the 'truth', could also be interpreted as an abdication of responsibility. Indeed, they did not state any intent to spend time uncovering the reality or cause(s) of the situation.

Far from being rich, self-reflective narratives where tourists try to make sense of their holiday experiences (see Carù and Cova 2006), the blogposts examined in this study were superficial and descriptive. Indeed, from the evidence provided in this study it seems Mkono (2016b) may be rather optimistic about tourists using social media to reflect upon experience to initiate change. On the contrary, these cruise bloggers revealed little ability to reflect, except for those few who claimed an intention to return to volunteer at some point in the future. However, these were self-interested rather than community related (Munar and Jacobsen 
2014), as they expressed delight at meeting the children and offering gifts ('Othering') rather than altruistic reflections on the impact of their visit on the long-term wellbeing of the visited children.

There was also an absence of shared reflexivity between bloggers - none of them responded to each other's posts, posting only discrete comments and experiences. Although the extent of interaction could be impacted by the type of blog platform examined, the individuality of this blogposts makes it extremely challenging for cruise researchers to respond to Bramwell et al.'s (2017) call for more research on how tourists interact and engage with others via social media. Because there was little evidence of bloggers learning from peer experiences, their own frames of references were rarely challenged (Mkono 2016b; Jansson 2018). Furthermore, none of the posts gathered in this study reveal the bloggers shared traits with Mkono and Tribe's (2017) reviewers' role of activist, although there was a hint of the social critic in one post that queried staff gratuities.

Based on their superficial and descriptive comments with regard to sustainability, it is difficult to determine whether these cruise passengers were unaware of any negative impact of the cruise, or had little interest in educating themselves about the social, economic and environmental impacts of their holidays. This may be a result of filtering personal observations based on the audience they are reaching. Bloggers may not reflect on all of their observations, and indeed may filter reflections according to the platform and audience as well as their curated online identity. Some may purposely not voice certain anxieties that may cast their own behaviour in a negative light. This is a further limitation of using travel blogs on face value. While one person openly queried the system of gratuities they did not linger over the issue or invite others to comment. Instead, they managed their dissonance by complying with tipping policy. The single comment on pollution was couched in terms of its effect on the passenger's holiday, thus revealing an egocentric narrative. Indeed, many of the blogs were self-interested, echoing Munar and Jacobsen's (2014) study that revealed bloggers (as opposed to Facebook users and online reviewers) were more likely to identify with these drivers for using this form of social media. Examples of such motivations include wanting to share experiences, a desire to maintain social connections and friendships and not be critical or self-reflective.

To conclude, while these blogs provided a platform to explore passengers' understanding of sustainability in cruising, their power for social advocacy appears to be limited. This suggests blogs purposefully created to educate, discuss, and share all aspects of sustainability in cruise tourism, and to advocate for change, may garner more critical reflections among tourists. Understanding if and how consumers discuss sustainable issues in tourism, and how they talk about it with regard to cruising, in any forum, whether on or offline, is vital for sustainable initiatives in the tourism and hospitality industry to succeed. There is 
clearly a lack of knowledge among cruise passengers about the issues associated with sustainable cruising, and this needs to be remedied if the industry is to be called to account by their customers for their unsustainable policies and practices. Given the blogposts in this study were unprompted and reflect only what the writers believed important to mention, it is safe to conclude the majority of passengers at present cruise without a conscience.

This study has inspired a number of practical on- and offline recommendations to encourage greater awareness, understanding and critical reflection on the sustainability of the cruise industry. Online, there currently exist web platforms with different purposes where information about cruise lines, destinations and related content is disseminated, debated and shared. These consist of large commercial forums, professional blogs and also research platforms run by critical bloggers and social activists. The world's largest online commercial cruise community Cruise Critic, where people review cruises, connect with either former work colleagues or fellow passengers, is administered by an individual who is a powerful gatekeeper in terms of controlling topics, direction and content. The forum is uncritical, very pro-cruise and offers little opportunity for people to comment on sustainable issues in cruise. Professional blogs are funded through promoting companies, cruise experiences and itineraries, and so they tend to be pro-cruise and mostly uncritical of the industry on its sustainability. The final group of people operate blogs that are more critical of the cruise industry, but their bespoke nature means they have limited spreadability. Only two of these are in existence - cruisejunkie.com and cruiselawnews.com, both operated by individuals who have been critical of the industry's practices for several decades. What is needed across all platforms are more prompted discussions and reflections of the sustainable aspects raised in this paper. Areas of particular concern are for example, social dimension issues such as staff working conditions, tipping policies, emotional labour, the 'Othering' of employees and/or destination residents, as well as economic and environmental aspects of sustainability. Advocates for sustainability in tourism and hospitality therefore need to approach the gatekeepers of general online cruise communities such as Cruise Critic to encourage them to open their forums and allow discussion on these pertinent issues.

In line with suggestions about joint responsibility for sustainability between business owners and guests (see Cavagnaro et al. 2018), some cruise lines need to proactively work with passengers to develop a sustainable approach to cruising (Sheppard 2010). Likewise, passengers need to take more responsibility in engaging in these conversations. In particular, companies that target the mass market passenger, could supplement their enrichment programmes to include expert talks, for example on how to respect port communities and cultures, not exoticising staff and/or local people and the importance of bringing garbage back on-board after excursions. Several cruise lines already offer Q \& A sessions on ship technology to 
explain their waste management programmes. However, such an approach to corporate social responsibility (CSR) is often seen as a PR exercise, with an emphasis on showcasing cost-effective environmental technologies rather than an honest appraisal of one of the impacts of cruise tourism. What is required is greater transparency from cruise companies in terms of educating passengers about these issues, but of equal importance is the deployment of sustainability champions among all cruise lines. However, while some of the smaller lines embrace sustainability (such as Seabourn, Windstar), it is unlikely mass market cruise brands will heed such recommendations.

The findings of this article prompt a suggestion for further investigation by social activists interested in sustainable tourism to develop critical and informational research blogs about cruising. These blogs need to be educational and written in a concise and accessible style to encourage community members to go beyond superficial and descriptive accounts and honestly reflect on the three dimensions of sustainability in cruise. Careful consideration also needs to be given to the everyday language or keywords used to attract people to the blog and to increase spreadability of the issues under discussion. These might include 'tipping', 'garbage' and 'emotion work.' Given that blogs capture what people talk about as much as what they do not, these blogs need to encourage interactivity so as to facilitate debate and interaction, in a quest to develop a greater social conscience among tourists about their travel choices. Finally, any research on blog communities needs to take account of the different categories of passenger, such as nationality, age, cruise experience, and types of cruise product - whether niche, small ship or mass market and individual cruise line.

Notes

1. 'Auto-tipping', or 'auto-gratuities' refers to how cruise lines add gratuities to the on-board account of passengers in a pre-determined set amount per person per day (usually $\$ 11-\$ 16$ ), to cover tips for waiters, wait staff, maitre d's, cabin stewards, etc. This amount can also be pre-paid before the cruise and replaces the traditional system of passengers giving cash in an envelope at the end of their cruise to staff that have served them. It is an expression of thanks and is customary in the US when a service has been provided.

\section{References:}

Adler, J. (1989), 'Origins of sightseeing', Annals of Tourism Research, 16:1, pp. 7-29.

Auger, P. and Devinney, T. M. (2007), 'Do what consumers say matter? The misalignment of Preferences with unconstraint ethical intentions', Journal of Business Ethics, 76:4, pp. 361-383. 
Baekkelund, A. (1999), 'Solving the people pollution problem', In R. Klein (2011), 'Responsible cruise tourism: Issues of cruise tourism and sustainability', Journal of Hospitality and Tourism Management, 18:1, pp. 107-116.

Baum, T. (2018), 'Sustainable human resource management as a driver in tourism policy and planning: A serious sin or omission?', Journal of Sustainable Tourism, 26:6, pp. 873-889.

Bonilla-Priego, M. J., Font, X., and del Rosario Pacheco-Olivares, M. (2014), 'Corporate sustainability reporting index and baseline data for the cruise industry’, Tourism Management, 44, pp. 149-160.

Bosangit, C., Hibbert, S. and McCabe, S. (2015), "If I was going to die I should at least be having fun": Travel blogs, meaning and tourist experience', Annals of Tourism Research, 55, pp. 1-14.

Bramwell, B., Higham, J., Lane, B., and Miller, G. (2017), 'Twenty-five years of sustainable tourism and the Journal of Sustainable Tourism: Looking back and moving forward', Journal of Sustainable Tourism, 25:1, pp. 1-9.

Braun, V. and Clarke, V. (2006), 'Using thematic analysis in psychology', Qualitative Research in Psychology, 3:2, pp. 77-101.

Brida, J. G. and Zapata, S. (2010), 'Cruise tourism: economic, socio-cultural and environmental impacts', International Journal of Leisure and Tourism Marketing, 1:3, pp. 205-226.

Budeanu, A. (2013), 'Sustainability and tourism social media', in A. M. Munar, S. Gymóthy, and C. Liping (eds), Tourism Social Media: Transformations in Identity, Community and Culture, Bingley: Emerald, pp. 87-103.

Burrai, E., Mostafanezhad, M., and Hannam, K. (2017), 'Moral assemblages of volunteer tourism development in Cusco, Peru', Tourism Geographies, 19:3, pp. 362-377.

Carù, A. and Cova, B. (2006), 'How to facilitate immersion in a consumption experience: Appropriation operations and service elements', Journal of Consumer Behaviour, 5:1, pp. 4-14.

Cavagnaro, E., Düweke, A. and Melissen, F. (2018), 'The host-guest relationship is the key to sustainable hospitality: Lessons learned from a Dutch case study', Hospitality and Society, 8:1, pp. 23-44.

Channel 4 (2012), Cruises undercover: The truth below decks, Dispatches, $1^{\text {st }}$ October. ITN productions.

Chin, C. (2008), Cruising in the Global Economy: Profits, Pleasure and Work at Sea. Aldershot: Ashgate.

Chen, Y-C., Shang, R-A. and Li, M-J. (2014), 'The effects of perceived relevance of travel blogs' content on the behavioural intention to visit a tourist destination', Computers in Human Behaviour, 30, pp. 787799.

CLIA (Cruise Lines International Association) (2017), 2017 Cruise Industry Outlook.

Dowling, R. and Weeden, C. (2017), 'The World of Cruising', in R. Dowling and C. Weeden (eds), Cruise Ship Tourism, 2nd ed., Wallingford: CABI, pp. 1-39.

Frantz, D. (1999), 'For Cruise Ships' Workers Much Toil, Little Protection', New York Times. December 24, 1999. 
Garrigós-Simón, F., Galdón-Salvador, J. L. and Gil-Pechuán, I. (2015), 'The economic sustainability of tourism growth through leakage', Tourism Economics, 21:4, pp. 721-739.

Gauntlett, D. and Horsley, R. (2004), Web. Studies (2 ${ }^{\text {nd }}$ ed.), London: Arnold.

Goffman, E. (1961), 'Asylums', New York: Anchor. In S. J. Tracy, (2000), 'Becoming a character for commerce: Emotion labour, self-subordination, and discursive construction of identity in a total institution', Management Communication Quarterly, 14:1, pp. 90-128.

Hall, C. M., Wood, H. and Wilson, S. (2017), 'Environmental reporting in the cruise industry, in R. Dowling and C. Weeden (eds), Cruise Ship Tourism, 2nd ed., Wallingford: CABI, pp. 441-464.

Hanna, P., Scarles, C., Cohen, S., and Adams, M. (2016), 'Everyday climate discourses and sustainable tourism', Journal of Sustainable Tourism, 24:12, pp. 1624-1640.

Hanna, P., Font, X., Scarles, C., Weeden, C. and Harrison, C. (2018), 'Tourist destination marketing: From sustainability myopia to memorable experiences', Journal of Destination Marketing and Management, 9, pp. 36-43.

Higham, J. and Cohen, S. (2011), 'Canary in a coalmine: Norwegian attitudes towards climate change and extreme long-haul air travel to Aotearoa/New Zealand'. Tourism Management, 32, pp. 98-105.

Higham, J. and Miller, G. (2018), 'Transforming societies and transforming tourism: Sustainable tourism in times of change', Journal of Sustainable Tourism, 26:1, pp. 1-8.

Hine, C. (2011), 'Internet research and unobtrusive methods', Social Research Update 61, University of Surrey. http://sru.soc.surrey.ac.uk/SRU61.pdf. Accessed 18 February 2018.

Hochschild, A. (1983), The Managed Heart, Berkeley: University of California Press.

Hookway, N. (2008), 'Entering the blogosphere': Some strategies for using blogs in social research, Qualitative Research, 8:1, pp. 91-113.

Hookway, N. and Snee, H. (2017), 'The Blogosphere', in Fielding, N. G., Lee, R. M. and Blank, G. (eds), The SAGE Handbook of Online Research Methods, London: SAGE, pp. 380-398.

Iaquinto, B. L. (2015), “I recycle, I turn out the lights": understanding the everyday sustainability practices of backpackers', Journal of Sustainable Tourism, 23:5, pp. 577-599.

Jansson, A. (2018), 'Rethinking post-tourism in the age of social media', Annals of Tourism Research, 69, pp. 101-110.

Johnson, D. (2002), 'Environmentally sustainable cruise tourism: a reality check', Marine Policy, 26:4, pp. 261-270.

Jones, P., Hillier, D. and Comfort, D. (2017), 'The two market leaders in ocean cruising and corporate sustainability', International Journal of Contemporary Hospitality Management, 29:1, pp. 288-306.

Juvan, E. and Dolnicar, S. (2014), 'The attitude-behaviour gap in sustainable tourism', Annals of Tourism Research, 48, pp. 76-95. 
Klein, R. (2009), Getting a grip on cruise ship pollution, Washington: Friends of the Earth. https://1bps6437gg8c169i0y1drtgz-wpengine.netdna-ssl.com/wp-

content/uploads/wpallimport/files/archive/Getting-a-grip-on-cruise-ship-pollution.pdf. Accessed 8 December 2017.

(2011), 'Responsible cruise tourism: Issues of cruise tourism and sustainability', Journal of Hospitality and Tourism Management, 18:1, pp. 107-116.

Kurtz, L. C., Trainer, S., Beresford, M., Wutich, A., and Brewis, A. (2017), 'Blogs as elusive ethnographic texts: Methodological and ethical challenges in qualitative online research', International Journal of Qualitative Methods, 16, pp. 1-12.

Larsen, S., Wolff, K., Marnburg, E. and Øgaard, T. (2013), 'Belly full, purse closed: Cruise line passengers' expenditures’, Tourism Management Perspectives, 6, pp. 142-148.

Lee, T. H., Jan, F-H. and Yang, C-C. (2013), 'Conceptualizing and measuring environmentally responsible behaviours from the perspective of community-based tourists', Tourism Management, 36, pp. 454-468.

Lester, J-A. and Weeden, C. (2004), 'Stakeholders, the natural environment and the future of Caribbean cruise tourism', International Journal of Tourism Research, 6:1, pp. 39-50.

Leung, D., Law, R., von Hoof, H. and Buhalis, D. (2013), 'Social media in tourism and hospitality: a literature review', Journal of Travel \& Tourism Marketing, 30:1-2, pp. 3-22.

London, W. R., Moyle, B. D. and Lohmann, G. (2017), 'Cruise infrastructure development in Auckland, New Zealand: A media discourse analysis (2008-2016)', Asia Pacific Journal of Tourism Research, 22:6, pp. 615-633.

Mack, C. (n.d.), Responsible Tourism what does it actually mean? [online] Available at: https://www.responsibletravel.com/holidays/responsible-tourism/travel-guide. [Accessed 1 March 2018].

MacLellan, R. (2016), LIAT, taxes and Caribbean tourism. Available http://dominicanewsonline.com/news/homepage/features/commentary/commentary-liat-taxesand-caribbean-tourism/ Accessed 23 February 2018.

MacNeill, T. and Wozniak, D. (2018), 'The economic, social and environmental impacts of cruise tourism', Tourism Management, 66, pp. 387-404.

Maher, P. T. (2012), 'Expedition cruise visits to protected areas in the Canadian Arctic: Issues of sustainability and change for an emerging market'. Tourism: An International Interdisciplinary Journal, 60:1, pp. 55-70.

Markham, A. N. and Buchanan, E.A. (2012), Ethical decision-making and Internet Research: Recommendations from the AoIR Ethics Working Committee. https://aoir.org/reports/ethics2.pdf. Accessed 18 February 2018.

McDonald, S., Oates, C. J., Thyne, M., Timmis, A. J., and Carlile, C. (2015), 'Flying in the face of environmental concern: Why green consumers continue to fly', Journal of Marketing Management, 31:1314, pp. 1503-1528. 
McIntosh, A. J. and Zahra, A. (2007), 'A cultural encounter through volunteer tourism: Towards ideals of sustainable tourism', Journal of Sustainable Tourism, 15:5, pp. 541-556.

McKercher, B., Prideaux, B., Cheung, C. and Law, R. (2010), 'Achieving voluntary reductions in the carbon footprint of tourism and climate change', Journal of Sustainable Tourism, 18:3, pp. 297-317.

Miller, G., Rathouse, K., Scarles, C., Holmes, K. and Tribe, J. (2010), 'Public understanding of sustainable tourism', Annals of Tourism Research, 37:3, pp. 627-645.

Mkono, M. (2012), 'Netnographic tourist research: The Internet as a virtual fieldwork site', Tourism Analysis, 17, pp. 553-555.

(2016a), 'Sustainability and Indigenous tourism insights from social media: worldview differences, cultural friction and negotiation', Journal of Sustainable Tourism, 24:89, pp. 1315-1330.

(2016b), 'The reflexive tourist', Annals of Tourism Research, 57, pp. 206-219.

Mkono, M. and Tribe, J. (2017), 'Beyond reviewing: Uncovering the multiple roles of tourism social media users', Journal of Travel Research, 56:3, pp. 287-298.

Munar, A. M., and Jacobsen, J.Kr.S. (2014), 'Motivations for sharing tourism experiences through social media', Tourism Management, 43, pp. 46-54.

Nilan, P., Artini, L. P., and Threadgold, S. (2014), 'Contemporary Balinese cruise ship workers, passengers, and employers', in V. K. Haskins and C Lowrie (eds), Colonization and Domestic Service: Historical and Contemporary Perspectives. New York City: Routledge.

Olive, R. (2012), 'Making friends with the neighbours: Blogging as a research method', International Journal of Cultural Studies, 16:1, pp. 153-174.

Oz, M. (2015), 'Social media utilization of tourists for travel-related purposes', International Journal of Contemporary Hospitality Management, 27:5, pp. 1003-1023.

Rokka, J. and Moisander, J, (2009), 'Environmental dialogue in online communities: negotiating ecological citizenship among global travellers', International Journal of Consumer Studies, 33, pp. 199-205. doi: 10.1111/j.1470-6431.2009.00759.x

Seatrade Cruise (2017), Seatrade Whitepaper on the future of cruise ships, http://ubm.seatradecruiseevents.com/the-future-of-cruise-ships-5/. Accessed 23 August 2017.

Scarles, C. (2012), 'The photographed other: Interplays of agency in tourist photography in Cusco, Peru', Annals of Tourism Research, 39:2, pp. 928-950.

Sheppard, V. (2010), 'Exploring the ethical standards of Alaska cruise ship tourists and the role they play inadvertently play in the unsustainable practices of the cruise ship industry', in M. Lück, P. T. Maher and E. J. Stewart (eds), Cruise Tourism in Polar Regions. London: Earthscan, pp. 75-92.

Snee, H (2010), 'Using blog analysis', http://eprints.ncrm.ac.uk/1321/2/10-toolkit-blog-analysis.pdf. Accessed 02 February 2018. 
(2013a), 'Doing something 'worthwhile': intersubjectivity and morality in gap year narratives', The Sociological Review, 62, pp. 843-861.

(2013b), 'Making ethical decisions in an online context: Reflections on using blogs to explore narratives of experiences', Methodological Innovations Online, 8:2, pp. 52-67.

Sotiriadis, M. (2017), 'Sharing tourism experiences in social media: A literature review and set of suggested business strategies', International Journal of Contemporary Hospitality Management, 29:1, pp. 179-225.

Spracklen, K. (2013), Whiteness and Leisure, Basingstoke, Hants: Palgrave MacMillan.

Terry, W. C. (2011), 'Geographic limits to global labour market flexibility: The human resources paradox of the cruise industry', Geoforum, 42, pp. 660-670.

(2017), 'Flags of Convenience and the global cruise market', in R. Dowling and C. Weeden (eds.), Cruise Ship Tourism, 2nd ed., Wallingford: CABI.

Tourism Concern. (2016), Should you go on a Cruise? [online] Available at: https://www.tourismconcern.org.uk/should-you-go-on-a-cruise/. [Accessed 1 March 2018].

Tracy, S. J. (2000), 'Becoming a character for commerce: Emotion labour, self-subordination, and discursive construction of identity in a total institution', Management Communication Quarterly, 14:1, pp. 90-128.

van Bets L. K. J., Lamers, M. A. J. and van Tatenhove, J. P. M. (2017), 'Governing cruise tourism at Bonaire: A networks and flow approach', Mobilities, 12:5, pp. 778-793.

Watson, B. (2015), Murky waters: the hidden environmental impacts of your cruise, The Guardian, 5 January. $\quad$ https://www.theguardian.com/sustainable-business/2015/jan/05/cruise-ship-holidaysenvironmental-impact. Accessed 20 February.

Weeden, C. (2015), 'Legitimization through corporate philanthropy: A cruise case study', Tourism in Marine Environments, 10:3-4, pp. 211-223.

Weeden, C., Lester, J-A. and Thyne, M. (2011), 'Cruise tourism: emerging issues and implications for a maturing industry', Journal of Hospitality and Tourism Management, 18:1. pp. 26-29.

Wood, R. E. (2000), 'Caribbean cruise tourism: Globalisation at sea', Annals of Tourism Research, 27:2, pp. 345-370.

Woodside, A. (2010), Case Study Research: Theory, Methods, Practice. UK: Emerald Group Publishing.

Zehrer, A., Crotts, J. C. and Magnini, V. P. (2011), The perceived usefulness of blog postings: An extension of the expectancy-disconfirmation paradigm. Tourism Management, 32:1, pp. 106-113.

Zhang, H. Q., Fan, D. X. F., Tse, T. S. M. and King, B. (2016), 'Creating a scale for assessing socially sustainable tourism', Journal of Sustainable Tourism, 25:1, pp. 61-78. 